\title{
Improved quality of life among adolescents with attention-deficit/hyperactivity disorder is mediated by protective factors: a cross sectional survey
}

\author{
Jorun Schei ${ }^{i^{*}}$, Torunn Stene Nøvik ${ }^{1,2 \dagger}$, Per Hove Thomsen ${ }^{1,3 \dagger}$, Marit S Indredavik ${ }^{1,2+}$ and Thomas Jozefiak ${ }^{1,2+}$
}

\begin{abstract}
Background: The aim of this study was to assess the role of protective factors as mediators and/or moderators of the relationship between coexisting emotional and conduct problems and quality of life (QoL) among adolescents with attention-deficit/hyperactivity disorder (ADHD).

Methods: The sample consisted of 194 adolescents with ADHD. Participants completed measures of individual competencies, family cohesion and social support, and QoL. Coexisting emotional and conduct problems were assessed using the Strength and Difficulties Questionnaire.

Results: Individual competencies and social support mediated the association between emotional and conduct problems and QoL. Family cohesion was associated with both emotional and conduct problems. No moderating effects of protective factors and coexisting problems were found.

Conclusions: The assessment of individual competencies, social resources, and family cohesion may identify potential treatment goals for adolescents with ADHD and coexisting problems, and may contribute to improvements in QoL.
\end{abstract}

Keywords: ADHD, Adolescence, Coexisting problems, Protective factors, QoL

\section{Background}

Attention-deficit/hyperactivity disorder (ADHD) is a heterogeneous and composite disorder [1] that is characterized by symptoms of inattention, hyperactivity, and impulsivity, which affect functioning in academic, social, and family contexts [2,3]. Adolescents with ADHD and coexisting emotional and conduct problems exhibit an increased risk of criminality [4], substance abuse [5], psychiatric admissions [6], premature death [7], poorer psychosocial functioning [8], and quality of life (QoL) [9] than do adolescents with ADHD without coexisting problems. Although ADHD is considered a strongly hereditary disorder [10], environmental factors in early life may also be important risk factors for the development of this condition [11]. The literature shows that individual and environmental factors may interact with genes to affect brain maturation among

\footnotetext{
* Correspondence: jorun.schei@ntnu.no

${ }^{\dagger}$ Equal contributors

'Regional Centre for Child and Youth Mental Health and Child Welfare, Norwegian University of Science and Technology, Pb 8905 MTFS, 7491

Trondheim, Norway

Full list of author information is available at the end of the article
}

individuals with ADHD during childhood and adolescence [12]. Thus, the investigation of risk and protective factors that are important for outcome among adolescents with ADHD is critical. Although the impact of coexisting disorders on QoL has been documented among adolescents with ADHD [9,13], little is known about which protective factors, if any, mediate and/or moderate this relationship.

Protective factors include both individual and environmental factors, and can be measured [14]. These factors lessen child maladjustment after life events [15]. Individual factors include competencies such as structured style, social competence, and personal competence. Structured style relates to executive functioning skills, e.g., planning, organization, and goal orientation. Environmental factors include social resources and family cohesion. Social resources address social support, such as having friends. A substantial proportion of ADHD patients have deficits in executive functioning tasks, which could be a causal factor for ADHD symptoms in a subset of patients [16,17]. ADHD patients also have poor social functioning (i.e., possessing a positive social orientation) and personal competence 
(i.e., self-esteem and self-efficacy) [18]. Poor social competence has been associated with conduct and emotional problems [19], including ADHD [20], and poor self-esteem plays a role in the association between social phobia and depression [21].

Coexisting emotional and conduct problems are risk factors for an unfavorable outcome for adolescents with ADHD [4-7,22]. We recently found that coexisting emotional and conduct problems in adolescents with ADHD were associated with low self-reported family functioning [23]. Rinsky and Hinshaw [24] found that childhood planning abilities predicted comorbid emotional and behavioral problems and social functioning in adolescence. The authors [24] reported that social functioning mediated the relationship between planning abilities and comorbidities, and that comorbidity mediated the relationship between planning abilities and social functioning.

QoL is a multidimensional concept and has various definitions [25]; nevertheless, it is commonly referred to as subjectively perceived well-being and satisfaction within several life domains [26], such as physical and mental health, friends, family, school, and time alone. Among a clinical sample of children with various diagnoses, it was shown that it is possible to improve QoL without reducing symptoms, which demonstrates the importance of assessing QoL [27]. A large European study [13] that assessed multiple factors that are possibly associated with QoL among children and adolescents with ADHD found that the presence of peer problems and emotional problems was most strongly associated with poor QoL outcomes. However, to date, few studies have addressed why adolescents with ADHD and coexisting emotional and conduct problems have impaired QoL [9].

For children and adolescents with ADHD, medical treatment is one of the major options to decrease ADHD symptoms and improve psychosocial functioning and QoL [25,28-30]. However, the complex nature of ADHD means that several channels of intervention are needed, especially in comorbid cases [31]. These interventions might include peer and friendship coaching [32] and organizational training [33].

Previous research has focused on the direct relationships between psychopathology and QoL $[9,13]$. However, protective factors may mediate and/or moderate the relationship between coexisting emotional problems and conduct problems and be considered as targets of treatment $[9,34]$. Therefore, we aimed to assess the mediating and moderating effect of individual competencies, family cohesion, and social resources on the relationship between coexisting emotional problems and conduct problems and QoL. By exploring these relationships in a sample of adolescents with ADHD, we hypothesized that the direct effect between emotional and conduct problems and QoL is mediated by individual competencies, family cohesion, and social resources, which implies that better protective factors decreased the negative effect of risk factors on QoL. Our second hypothesis was that adolescents in the sample who were receiving medication have fewer emotional and conduct problems and better QoL. Finally, our third hypothesis was that protective factors moderate the effect of coexisting problems and ADHD symptom level on QoL. We included key covariates in the direct and final path model (age, sex, level of ADHD symptoms, and medication) to determine the specificity of the protective factors. Associations in the path model were also adjusted for all other variables included in it.

\section{Methods}

\section{Clinical sample}

This study was part of The Health Survey performed by the Department of Child and Adolescent Psychiatry (CAP) at St. Olav's University Hospital in Norway. This was a cross-sectional study of a defined clinical population. The catchment area was a county in Norway with 303,664 inhabitants, which includes urban and rural areas. The Department of CAP at the University Hospital covers all inhabitants in the county. The inclusion criteria were as follows: referred adolescents, age between 13 and 18 years, and presence of at least one attendance to the clinic between February 15, 2009 and February 15, 2011. Exclusion criteria were as follows: major difficulties in answering the questionnaire because of psychiatric state, cognitive dysfunctions, or lack of sufficient language skills. Emergency patients were invited to take part once stabilized. Among the 1,648 eligible and invited adolescents, 717 (43.5\%) participated in the CAP survey. This survey and the representativeness of the sample have been described in detail previously [19]. Of the 717 participants, 243 adolescents were diagnosed with ADHD. Patients with a missing Strengths and Difficulties Questionnaire (SDQ) $[35,36]$ were excluded from the study $(n=49)$, leaving 194 participants in the present study (final response rate, 34.8\%): 87 girls and 107 boys.

\section{Procedure}

Newly referred patients and patients who were already enrolled in the CAP clinic received oral and written invitations to participate in the study at first attendance after commencement of the project. The participating adolescents responded to an electronic questionnaire and data were collected from clinical charts. The ADHD rating scale was collected from the period of assessment prior to the initiation of medical treatment. Parents also responded to a questionnaire with items related to educational level. 


\section{Measures}

\section{Sociodemographic information}

The parents of the participants completed a demographic form with information about age, sex, and socioeconomic status (SES). The highest educational level of parents on an 8-point Hollingshead scale was used to estimate SES [37].

\section{Clinical diagnosis}

Diagnoses were collected from clinical charts and were established according to the International Statistical Classification of Diseases and Related Health Problems (10th revision (ICD-10) [38] multiaxial diagnostic system (i.e., axes I-VI). All diagnoses were made by a clinical psychologist or a child and adolescent psychiatrist based on the available clinical information. The CAP clinic's standardized procedure for the assessment and diagnosis of hyperkinetic disorders is based on the national guideline for the assessment and treatment of ADHD [39]. This guideline, similar to other established ADHD guidelines [40], requires a clinical diagnostic interview based on ADHD as described in the Diagnostic and Statistical Manual of Mental Disorder 4th edition, text revision (DSM-IV-TR) [41], possible coexisting disorders, and a somatic assessment; it recommends the use of questionnaires filled out by the adolescent, parent, and teacher to obtain ADHD symptom scores (ADHD rating scale). The $I C D$-10 diagnosis of hyperkinetic disorder is referred to as ADHD in this study. The diagnostic criteria for hyperkinetic disorder are nearly identical to the criteria for ADHD combined type in the DSM-IV-TR [41], however, specifiers such as mainly attention problems or hyperactivity/impulsivity problems are not utilized in the $I C D-10$. A recent study of adults showed that DSM-IV-TR ADHD inattentive and hyperactive-impulsive types are less likely to qualify for a diagnosis of hyperkinetic disorder [42]. Coexisting disorders from clinical charts were not used in the present study.

\section{Medication}

nformation about medical treatment was collected from clinical charts, including prescribed medicines (methylphenidates, amphetamines, or atomoxetine). Data from the clinical charts verified that the patients had entered a stable phase with a documented effect of the medication.

\section{ADHD Rating Scale IV (ADHD-RS)}

ADHD symptoms were measured using the ADHD-RS, parent version [43]. The instrument contains 18 items that address ADHD symptoms based on the DSM-IV criteria. The items are measured on a 5-point scale, in which higher scores reflect higher frequencies of symptoms. The scale is organized into two sections, each with its own sum score. One reflects symptoms of inattention, whereas the other reflects hyperactivity and impulsivity.

\section{Strengths and Difficulties Questionnaire (SDQ)}

Coexisting problems were measured using the Norwegian version [35] of the SDQ [36]. This clinical and research instrument contains 25 items that address emotional and behavioral problems, as well as personal strengths [36]. The SDQ subscales have shown satisfactory to good internal consistency, and the stability of the basic psychometric properties of the SDQ has been demonstrated across clinical samples [44]. In the present study, the three subscales, Emotional Problems, Conduct Problems, and Hyperactivity/Inattention, were used as indicators of latent construct emotional problems, conduct problems, and hyperactivity/ inattention problems, respectively. The SDQ adolescent self-report exhibited satisfactory construct validity and internal consistency in a study performed by the original author; the Cronbach alphas of the self-report were as follows: total difficulties, 0.80 ; emotional problems, 0.66; conduct problems, 0.60; and hyperactivity/inattention, 0.67 [45]. Van Roy et al. [35] found the SDQ self-report to be appropriate for children and adolescents aged 10-19 years. Another study performed by the same authors divided the sample according to the following age groups: 10-13 (preadolescent), 13-16 (early adolescent), and 16-19 (late adolescent) years. The early and late adolescent groups had the following Cronbach alphas, respectively: emotional problems, .71 and .70; conduct problems, .59 and .54; and hyperactivity, .65 and .66 [46].

\section{Resilience Scale for Adolescents (READ)}

Protective factors were measured using the READ, which is a 23-item self-report scale that is based on a 5-point Likert scale [14]. Higher scores on the READ reflect lower degrees of resilience. The construct and convergent validity were adequately assessed. The READ is based on the Resilience Scale for Adults [47], and consists of the same five subscales: 1) Personal Competence, 2) Social Competence, 3) Structured Style, 4) Family Cohesion, and (5) Social Resources. The items on three subscales (i.e., Personal Competence, Social Competence, and Structured Style) were used as indicators of the latent concept individual competencies; items from the Family Cohesion and Social Resources subscales were used as indicators of two latent environmental protective factors. In the current study, READ showed satisfactory psychometric characteristics for the total scale $(\alpha=0.98)$ and for the three subscales: Personal Distributions $(\alpha=0.97)$, Family Cohesion $(\alpha=0.89)$, and Social Resources $(\alpha=0.91)$.

\section{Inventory of Life Quality in Children and Adolescents (ILC)}

QoL was measured using the Norwegian version [48] of the ILC $[49,50]$. This 7-item self-report inventory includes one item for global evaluation of QoL and six items that address the child's physical and mental health, perception of activities when alone, perceived relationships with friends and 
family, and functioning in school. Each item uses a 5-point Likert scale, with lower scores reflecting a higher QoL. In the present study, the seven items were used as indicators of the latent concept QoL. Reliability testing in the present study indicated good internal consistency $(\alpha=0.94)$. The construct validity of the ILC is also satisfactory [50].

\section{Ethics}

Written informed consent was obtained from adolescents and parents prior to inclusion, according to the study procedures of the CAP survey. Study approval was given by the Regional Committees for Medical and Health Research Ethics (CAP survey reference number: 4.2008.1393; present study: 2011/1772) and by the Norwegian Social Science Data Services (CAP survey reference number: 19976).

\section{Statistical analyses}

Statistical analyses were conducted using SPSS version 19 and Mplus version 7 [51]. The frequency of missing values was between $2 \%$ and $5 \%$. All missing values were imputed using full information maximum likelihood. We used a confirmatory factor analysis of the READ to validate the three subscales. The following indexes were used to assess the goodness of fit of the models [52]: the chi-squared test, the comparative fit index (CFI), the Tucker-Lewis index (TLI), and the root mean square error of approximation (RMSEA). Regarding CFI and TFI, values above 0.95 are considered indicators of good fit; for RMSEA, values below 0.06 are considered indicators of good fit [53]. The structural equation model was estimated using the weight least square parameter estimator (WLSMV), because of the categorical nature of the indicators. A saturated structural model was tested, in which all latent variables were regressed on each other and on the observable scales (see Figure 1). In addition to the mediator model, we tested if protective factors interacted with the Emotional Problems, Conduct Problems, and Hyperactivity/ Inattention SDQ scales in the model. Two-tailed tests $(p<0.05)$ were used to measure statistical significance.

\section{Results}

\section{Descriptive data of the sample}

See Table 1. The mean scores of the ADHD-RS were similar to those reported for another Norwegian clinical sample of adolescents with ADHD [54].

\section{Confirmatory factor analyses}

Confirmatory factor analyses using items from the three subscales of the READ were conducted using our sample of ADHD patients $(n=194)$. The 23-item model showed an acceptable model fit, $\chi^{2}(227)=495.790 ;$ CFI $=.949$; TLI $=.943$; RMSEA $=.078$, CI $[.069, .088]$. Standardized factor loadings are presented in Table 2.

\section{Measurement model}

The model showed an acceptable fit: $\mathrm{CFI}=.94$; TLI = .93; RMSEA $=.056$, CI $[.049, .063]$, with a significant chi-squared value, $\chi^{2}(524)=846.541, p=0.000$. The chi-squared/df-ratio was 1.62 , which is commonly regarded as acceptable [55].

\section{Path models}

\section{Protective factors as mediators of ADHD}

A model analyzing the direct effect of coexisting problems on QoL was developed (see Figure 2). In this model, a higher level of Emotional Problems $(\beta=0.535)$ and Conduct Problems $(\beta=0.165)$ and Increasing Age ( $\beta=0.143)$ decreased QoL.

The final path model, which also included indirect effects of protective factors and medicated/unmedicated adolescents, is shown in Figure 3. Emotional Problems was mediated by Individual Competencies; thus, the direct effect on QoL $(\beta=0.535)$ was reduced in the final path model $(\beta=0.241)$. Similarly, Conduct Problems was mediated by Social Resources, thus diminishing the direct effect on QoL $(\beta=0.165)$. A higher level of Conduct Problems was associated with lower Family Cohesion $(\beta=0.240)$ and Social Resources $(\beta=0.229)$ and with being unmedicated $(\beta=-0.261)$. A higher level of Emotional Problems was associated with lower Individual Competencies $(\beta=0.468)$, Family Cohesion $(\beta=0.314)$, and Social Resources $(\beta=0.411)$. A lower level of Individual Competencies $(\beta=0.285)$ and Social Resources $(\beta=0.418)$ was associated with a decreased QoL. Medical treatment was almost significantly associated with a better QoL in the present study $(\beta=-0.150, p=0.062)$. A higher level of Hyperactivity/Inattention was associated with decreased QoL when adjusted for all variables included in the final path model $(\beta=0.143)$. Increased Age was associated with decreased QoL $(\beta=0.120)$, similar to that observed in the direct effect model.

\section{Protective factors as moderators: interaction model}

Our analyses showed no interaction between coexisting problems (i.e., Emotional Problems, Conduct Problems, and Inattention/Hyperactivity) and protective factors (i.e., Individual Competencies, Family Cohesion, and Social Resources) and no effect on QoL. For example, Individual Competencies was not a moderator of the effect of Conduct Problems on QoL $(\beta=-0.034, p=0.644)$, of the effect of Emotional Problems on QoL $(\beta=0.005, p=0.644)$, or of Hyperactivity/Inattention on $\mathrm{QoL}(\beta=-0.023, p=0.221)$.

\section{Discussion}

The aim of this study was to assess the role of protective factors as mediators and moderators of the relationship between coexisting emotional problems and conduct problems and QoL among adolescents with ADHD. The results, based on self-reports, showed that protective factors 


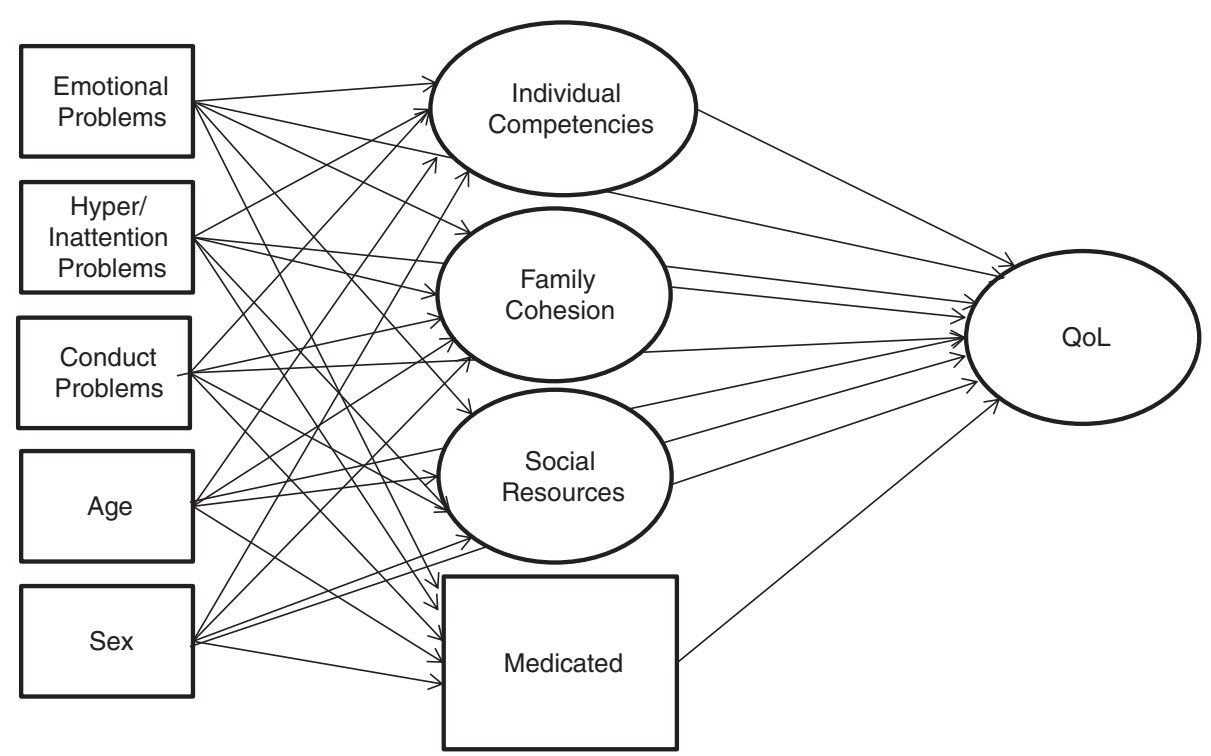

Figure 1 The tested mediator model.

mediated the association between emotional and conduct problems and QoL, even after adjusting for prescribed medication. Individual Competencies was the strongest mediator of the relationship between coexisting emotional problems and QoL. Furthermore, we found no significant interactions between coexisting factors and individual competencies, which indicates that there were no moderators.

The major finding of this study was that individual competencies, which include structured style, social competence, and personal competence, were the strongest mediators of the relationship between emotional problems and QoL among adolescents with ADHD. These results suggest that adolescents with ADHD and a better structured style, social competence, and personal competence are more protected from coexisting emotional problems, and that these factors are associated with a better QoL.

Table 1 Descriptive data of the study sample: 194 adolescents with ADHD

\begin{tabular}{lll}
\hline & Mean (SD) & n (\%) \\
\hline Age & $15.48(1.71)$ & \\
SES & $4.78(1.82)$ & \\
SDQ Emotional Problem scale & $4.23(2.76)$ & \\
SDQ Conduct Problem scale & $3.01(1.88)$ & \\
SDQ Hyperactivity/Inattention scale & $6.29(2.15)$ & \\
ADHD-RS Inattention scale & $18.73(5.67)$ & \\
ADHD-RS Hyperactivity/Impulsivity scale & $12.90(7.11)$ & \\
ADHD-RS Total Scale & $31.62(10.42)$ & \\
Medicated & & $148(76.3)$ \\
\hline
\end{tabular}

Note. SES, highest educational level of the parents.

SDQ, Strengths and Difficulties Questionnaire.

ADHD-RS, ADHD rating scale.
Table 2 Standardized factor loadings for the 23-item READ scale $(n=194)$

\begin{tabular}{ll}
\hline Item number and content & Standardized factor loadings \\
\hline Personal Dispositions & \\
7 goal orientation items & 0.76 \\
12 realism items & 0.55 \\
17 competence items & 0.77 \\
20 self-confidence items & 0.80 \\
26 positive outlook items & 0.69 \\
2 aims and objectives & 0.69 \\
8 planfulness items & 0.65 \\
13 organizational skill items & 0.65 \\
6 positive social orientation items & 0.76 \\
11 making contact items & 0.65 \\
22 humor items & 0.87 \\
25 comforting others items & 0.80 \\
Family Cohesion & \\
5 shared values items & 0.86 \\
15 familial agreement items & 0.81 \\
10 comfort items & 0.90 \\
21 common positive outlook items & 0.70 \\
24 support items & 0.86 \\
27 shared activities items & 0.72 \\
14 soncouragement items & \\
\hline
\end{tabular}




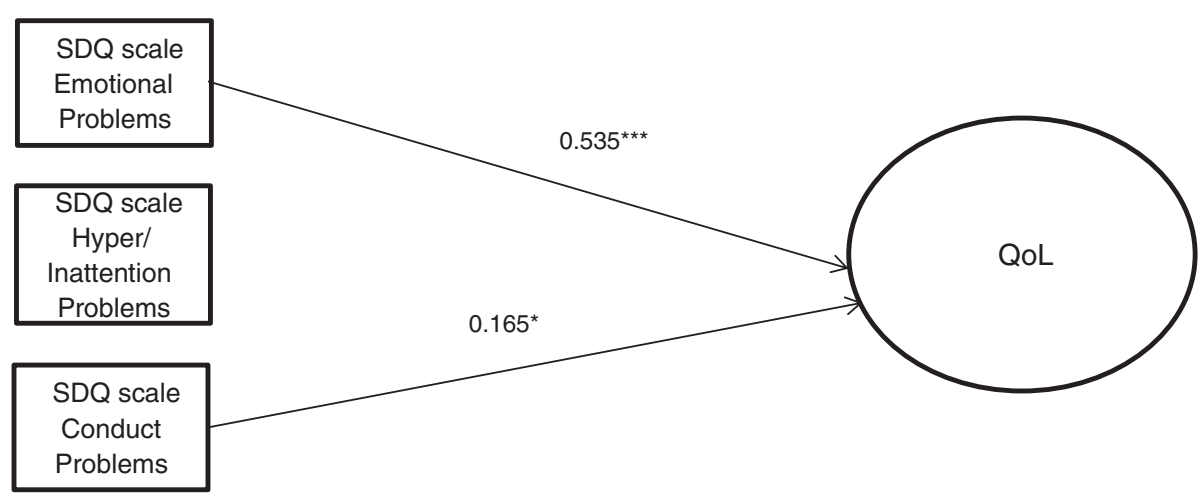

Figure 2 Path model with standardized estimates for direct effects without protective factors, adjusted for age and sex. Note. ${ }^{*} p<.05$, ${ }^{* *} p<.01,{ }^{* * *} p<.001 . S D Q-$ Strength and Difficulties Questionnaire.

Executive function impairments among children with ADHD are heterogeneous [16,56]. The present study assessed organizational and planning skills, which might be particularly important during adolescence, whereas different aspects of executive functioning may be more important among younger children [57]. Another study indicated that planning and organizational abilities predicted academic functioning above and beyond the impact of ADHD symptoms [58]. It has been suggested that social competence mediates the relationship between ADHD and depression in children [59]. Moreover, personal competence may be an influential factor in everyday life, as it was found to mediate the relationship between ADHD symptoms and test anxiety [60] and to mediate partially the relationship between ADHD symptoms and adjustment to college [61]. Our results indicate that social competence and personal competence might also mediate the relationship between coexisting emotional problems and QoL. The use of individual competencies might allow the implementation of more targeted interventions aimed at improving coexisting problems and QoL. Structured style, social competence, and personal competence are considered plastic brain functions, and some studies have found that cognitive training is beneficial for individuals with ADHD [62-65], including studies of adults [66]. Furthermore, findings from the ADHD literature suggest that medical treatment significantly improves social functioning and self-esteem $[19,67]$.

Our second finding was that social resources mediated the relationship between both emotional and conduct problems and QoL. Peer difficulties represent a significant area of impairment for adolescents with ADHD [13,68]. Our results indicate that ADHD patients with better social resources may be protected from coexisting emotional and conduct problems, and better Social Resources was associated with a greater QoL. Heiman [69] found that children with ADHD define friendship differently than do typically developing children. They tend to value certain characteristics in friendships that may conflict with those valued by their peer group, such as having fun compared

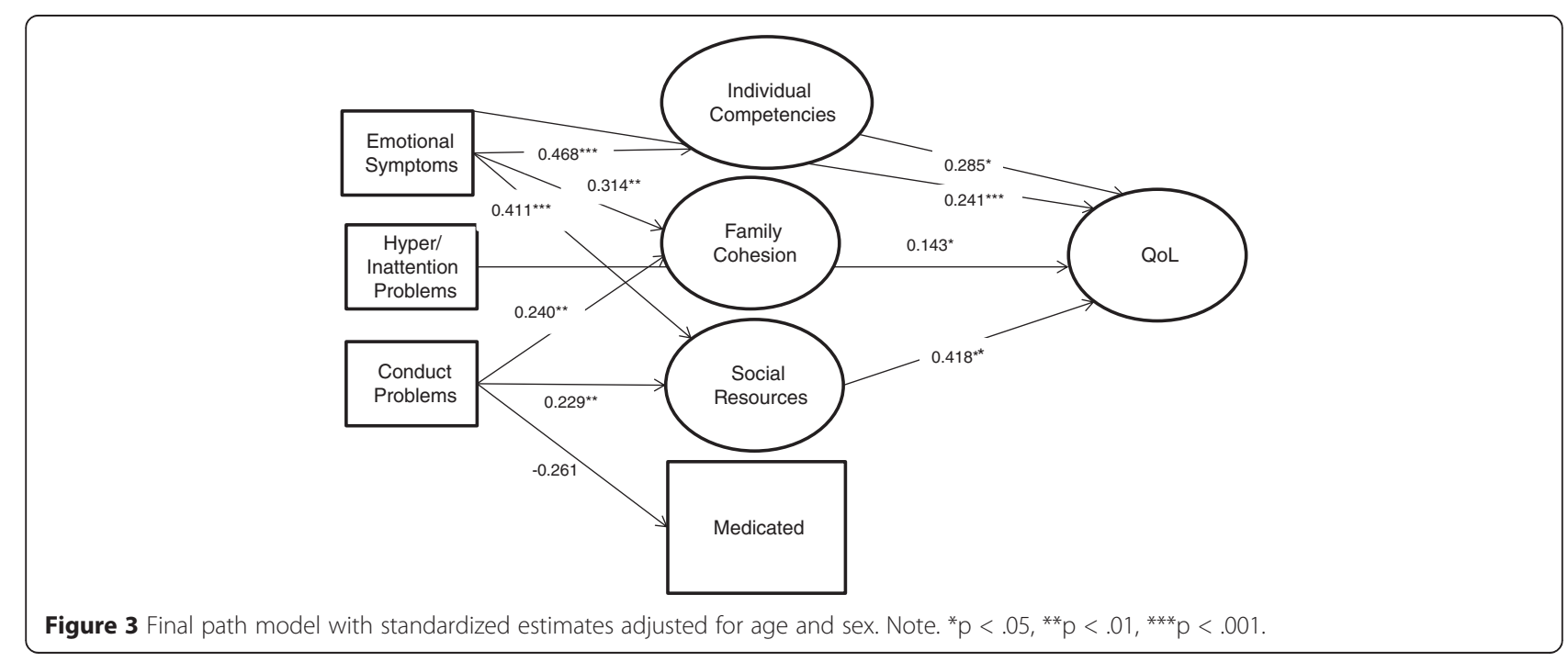


with receiving emotional support; this can lead to a decreased likelihood of developing mutually satisfying friendships [70]. Longitudinal studies suggest that peer rejection predicts later negative outcomes, including emotional and conduct problems [2,20]. Moreover, according to McQuade et al. [71], being socially successful combined with modest perceptions of competence is a protective factor against behavioral problems. Several studies have found that coexisting conduct problems in children with ADHD severely worsen the adult outcome [6,7]. Therefore, supporting protective factors that attenuate the risk beyond the effect of medical treatment may be of great importance in the comprehensive treatment of these children and adolescents. Further research on these relationships is recommended

Another finding was the association between coexisting emotional and conduct problems and family cohesion. In a previous study, we found that coexisting problems had an impact on family functioning [23]. Better family functioning, as experienced by the adolescents with ADHD, was associated with fewer emotional and conduct problems. These findings are in line with recent research suggesting that higher family cohesion mediates the effect of foster care on children's ADHD symptomatology [72]. Furthermore, positive development of executive functions, social competence, and peer outcomes has been associated with higher family cohesion, family functioning, and/or parentchild attachment during childhood [72,73]. We found no association between family cohesion and QoL; however, previous studies found that parental support was associated with QoL among college students with ADHD [74,75]. These differences in findings might be attributable to variations in the instruments used to measure QoL; in addition, the subjects included in the Grenwald-Mayes [74] and Wilmshurst et al. [75] studies were older than those reported in our study (mean age, 25 and 19 vs 15 years, respectively). The results of our study underline the importance of considering both individual and environmental factors in ADHD.

Finally, adolescents with ADHD who received medical treatment had fewer conduct problems, indicating a positive effect of medication on conduct problems, which is consistent with previous work [76]. Conversely, the level of emotional problems was unrelated to medication. The effect of medication on QoL did not quite reach statistical significance, which might have been caused by statistical power limitations. Some studies indicate that comorbid anxiety disorders are associated with a lower effect of medication on ADHD symptoms and psychosocial functioning, which leads to discontinuation of medical treatment [30]. A study of children and adolescents documented that, among treated individuals, about $6 \%$ were also treated for emotional disorders [77]. Some clinical samples of adolescents with ADHD have reported even higher levels of emotional problems [78]. In our sample, emotional problems included primarily coexisting problems, part of the ADHD symptomatology, or a side effect of medical treatment. However, the latter is somewhat less likely, because care is taken to minimize side effects [79]. Furthermore, our sample included a relatively high percentage of girls, who exhibit a higher prevalence of emotional problems during adolescence in both clinical and epidemiological studies [80,81].

The findings of the present study were limited by a low response rate, which could have led to imprecise results. Nevertheless, the reason for referral did not differ from the population of patients treated in the clinic during the study period. Another limitation was that the results were based only on self-reports. Previous studies have found that children with ADHD have a positive illusory bias and perceive their level of competence inaccurately [82,83]. Goodman [45] has described the sensitivity of the SDQ scale. The odds ratios for the emotional scale were similar for selfreports and parent reports, whereas the odds ratios for the conduct scale were higher in parent reports. This might indicate that conduct problems were underreported in the present study, which is in agreement with prior research [84]. Parent reports might have yielded different results regarding conduct problems. Conversely, self-report scales may increase awareness of internalizing problems [85]. A clinical interview with parents was not conducted, and the family structure was not assessed. Therefore, we were not able to adjust for parental ADHD or other chronic conditions in the analysis. Another limitation of the study was its cross-sectional design, which did not allow causal inferences based on the data. A longitudinal study would allow the assessment of reciprocal relationships between the variables, as well as the examination of the development of family functioning and QoL. Finally, the ADHD diagnosis was based on clinical $I C D-10$ diagnoses rather than on standardized semistructured child psychiatric interviews. Interrater reliability scores were not available; however, all diagnoses were established by an experienced child and adolescent psychiatrist or a clinical psychologist, and were based on standard national and international guidelines. Furthermore, the mean scores of the ADHD-RS were in the same range as those reported by other studies, including those of Norwegian clinical samples of adolescents with ADHD $[55,86]$.

\section{Conclusions}

The current study provided new information regarding the role of protective factors in the relationship between ADHD and coexisting emotional and conduct problems, and regarding the impact of these factors on QoL. Individual competencies, family cohesion, and social resources may reduce emotional problems and behavioral problems and improve QoL among adolescents with ADHD and among medicated individuals. The assessment of protective factors, in addition to risk factors, may identify potential treatment goals. 


\section{Competing interests}

Torunn Stene Nøvik received speaker's fees from Eli Lilly. Per Hove Thomsen received speaker's fees from Shire, Medice, and Novartis. The present work is unrelated to the above grants or relationships. The other authors report no conflicts of interest.

\section{Authors' contributions}

All authors contributed to the design of the study. JS analyzed the data. All authors contributed to the drafting and approved the final manuscript.

\section{Acknowledgments}

This study was financed by a PhD grant awarded to the first author by the Department of Research and Development, St. Olav's University Hospital, Medical Faculty. The CAP survey is a product of the collaboration between St. Olav's University Hospital and the Regional Centre for Child and Youth Mental Health and Child Welfare (RKBU), NTNU; it is also funded by Unimed Innovation at St. Olav's University Hospital and the Liaison Committee between the Central Norway Regional Health Authority and the NTNU. We thank the adolescents who participated in the CAP survey.

\section{Author details}

${ }^{1}$ Regional Centre for Child and Youth Mental Health and Child Welfare, Norwegian University of Science and Technology, Pb 8905 MTFS, 7491 Trondheim, Norway. ${ }^{2}$ Department of Child and Adolescent Psychiatry, St. Olavs Hospital Trondheim University Hospital, Pb 6810 Elgeseter, 7433 Trondheim, Norway. ${ }^{3}$ Psychiatric Hospital for Children and Adolescents, Aarhus University Hospital, Skovagervej 2, 8240 Risskov, Denmark.

\section{Received: 23 June 2014 Accepted: 27 April 2015}

\section{Published online: 07 May 2015}

\section{References}

1. Barkley RA, Fischer M, Smallish L, Fletcher K. Young adult outcome of hyperactive children: adaptive functioning in major life activities. J Am Acad Child Adolesc Psychiatry. 2006;45(2):192-202

2. Mrug S, Molina BS, Hoza B, Gerdes AC, Hinshaw SP, Hechtman L, et al. Peer rejection and friendships in children with attention-deficit/hyperactivity disorder: contributions to long-term outcomes. J Abnorm Child Psychol. 2012;40(6):1013-26.

3. Booster GD, Dupaul GJ, Eiraldi R, Power TJ. Functional impairments in children with ADHD: unique effects of age and comorbid status. J Atten Disord. 2012;16(3):179-89.

4. Dalsgaard S, Mortensen PB, Frydenberg M, Thomsen PH. Long-term criminal outcome of children with attention deficit hyperactivity disorder. Crim Behav Ment Health. 2013;23(2):86-98.

5. Dalsgaard S, Mortensen PB, Frydenberg M, Thomsen PH. ADHD, stimulant treatment in childhood and subsequent substance abuse in adulthood - a naturalistic long-term follow-up study. Addict Behav. 2014;39(1):325-28.

6. Dalsgaard S, Mortensen PB, Frydenberg M, Thomsen PH. Conduct problems, gender and adult psychiatric outcome of children with attention-deficit hyperactivity disorder. Br J Psychiatry. 2002;181:416-21.

7. Dalsgaard S, Østergaard SD, Leckman JF, Mortensen PB, Pedersen MG. Mortality in children, adolescents, and adults with attention deficit hyperactivity disorder: a nationwide cohort study. Lancet. 2015. doi:10.1016/ s0140-6736(14)61684-6.

8. Biederman J, Martelon M, Faraone SV, Woodworth KY, Spencer TJ, Wozniak JR. Personal and familial correlates of bipolar (BP)-I disorder in children with a diagnosis of BP-I disorder with a positive child behavior checklist (CBCL)-severe dysregulation profile: a controlled study. J Affect Disord. 2013;147(1-3):164-70.

9. Danckaerts M, Sonuga-Barke EJ, Banaschewski T, Buitelaar J, Dopfner M, Hollis C, et al. The quality of life of children with attention deficit/hyperactivity disorder: a systematic review. Eur Child Adolesc Psychiatry. 2010;19(2):83-105.

10. Gjone H, Stevenson J, Sundet JM. Genetic influence on parent-reported attention-related problems in a Norwegian general population twin sample. J Am Acad Child Adolesc Psychiatry. 1996;35(5):588-96. discussion 596-88.

11. Nigg J. What causes ADHD? New York: The Guilford Press New York; 2006.

12. Modesto-Lowe V, Yelunina L, Hanjan K. Attention-deficit/hyperactivity disorder: a shift toward resilience? Clin Pediatr (Phila). 2011;50(6):518-24.

13. Riley AW, Spiel G, Coghill D, Dopfner M, Falissard B, Lorenzo MJ, et al. Factors related to health-related quality of life (HRQOL) among children with
ADHD in Europe at entry into treatment. Eur Child Adolesc Psychiatry. 2006;15 Suppl 1:138-45.

14. von Soest T, Mossige S, Stefansen K, Hjemdal O. A validation study of the Resilience Scale for Adolescents (READ). J Psychopathol Behav Assess. 2010;32:215-25.

15. Rutter M. Resilience reconsidered: conceptual considerations, empirical findings, and policy implications. In: Shonkoff JP, Meisels SJ, editors. Handbook of early childhood intervention. 2nd ed. New York: Cambridge University Press; 2000. p. 651-82.

16. Roberts BA, Martel MM, Nigg JT. Are there executive dysfunction subtypes within ADHD? J Atten Disord. 2013. doi:10.1177/1087054713510349

17. Lambek R, Tannock R, Dalsgaard S, Trillingsgaard A, Damm D, Thomsen PH Validating neuropsychological subtypes of ADHD: how do children with and without an executive function deficit differ? J Child Psychol Psychiatry. 2010;51(8):895-904.

18. Harpin V, Mazzone L, Raynaud JP, Kahle J, Hodgkins P. Long-term outcomes of ADHD: a systematic review of self-esteem and social function. J Atten Disord. 2013. doi:10.1177/1087054713486516

19. Burt KB, Roisman Gl. Competence and psychopathology: cascade effects in the NICHD Study of Early Child Care and Youth Development. Dev Psychopathol. 2010;22(3):557-67.

20. Murray-Close D, Hoza B, Hinshaw SP, Arnold LE, Swanson J, Jensen PS, et al. Developmental processes in peer problems of children with attention-deficit/ hyperactivity disorder in the Multimodal Treatment Study of Children With ADHD: developmental cascades and vicious cycles. Dev Psychopathol. 2010;22(4):785-802

21. Vaananen JM, Isomaa R, Kaltiala-Heino R, Frojd S, Helminen M, Marttunen M. Decrease in self-esteem mediates the association between symptoms of social phobia and depression in middle adolescence in a sex-specific manner: a 2-year follow-up of a prospective population cohort study. BMC Psychiatry. 2014;14:79.

22. Biederman J, Petty CR, Clarke A, Lomedico A, Faraone SV. Predictors of persistent ADHD: an 11-year follow-up study. J Psychiatr Res. 2011:45(2):150-55.

23. Schei J, Jozefiak T, Novik TS, Lydersen S, Indredavik MS. The impact of coexisting emotional and conduct problems on family functioning and quality of life among adolescents with ADHD. J Atten Disord. 2013. doi:10.1177/ 108705713507976

24. Rinsky JR, Hinshaw SP. Linkages between childhood executive functioning and adolescent social functioning and psychopathology in girls with ADHD. Child Neuropsychol. 2011;17(4):368-90.

25. Coghill D, Danckaerts M, Sonuga-Barke E, Sergeant J, Group AEG. Practitioner review: quality of life in child mental health - conceptual challenges and practical choices. J Child Psychol Psychiatry. 2009;50(5):544-61.

26. Mattejat $F$, Remschmidt $H$. Assessing the quality of life of children and adolescents with psychiatric disorders - a review. Z Kinder Jugendpsychiatr Psychother. 1998;26(3):183-96

27. Bastiaansen D, Koot HM, Ferdinand RF. Psychopathology in children: improvement of quality of life without psychiatric symptom reduction? Eur Child Adolesc Psychiatry. 2005;14(7):364-70.

28. van der Kolk A, Bouwmans CA, Schawo SJ, Buitelaar JK, van Agthoven M Hakkaart-van RL. Association between quality of life and treatment response in children with attention deficit hyperactivity disorder and their parents. J Ment Health Policy Econ. 2014;17(3):119-29.

29. Faraone SV, Buitelaar J. Comparing the efficacy of stimulants for ADHD in children and adolescents using meta-analysis. Eur Child Adolesc Psychiatry. 2010;19(4):353-64.

30. Fredriksen M, Dahl AA, Martinsen EW, Klungsoyr O, Haavik J, Peleikis DE. Effectiveness of one-year pharmacological treatment of adult attention-deficit/ hyperactivity disorder (ADHD): an open-label prospective study of time in treatment, dose, side-effects and comorbidity. Eur Neuropsychopharmacol. 2014:24(12):1873-84.

31. Hinshaw SP, Arnold LE. For the MTA Cooperative Group. ADHD, multimodal treatment, and longitudinal outcome: evidence, paradox, and challenge. Wiley Interdiscip Rev. Cogn Sci. 2015;6(1):39-52.

32. Mikami AY, Lerner MD, Griggs MS, McGrath A, Calhoun CD. Parental influence on children with attention-deficit/hyperactivity disorder: II. Results of a pilot intervention training parents as friendship coaches for children. J Abnorm Child Psychol. 2010;38(6):737-49.

33. Abikoff H, Gallagher R, Wells KC, Murray DW, Huang L, Lu F, et al. Remediating organizational functioning in children with ADHD: immediate and long-term effects from a randomized controlled trial. J Consult Clin Psychol. 2013;81(1):113-28. 
34. Deault LC. A systematic review of parenting in relation to the development of comorbidities and functional impairments in children with attention-deficit/ hyperactivity disorder (ADHD). Child Psychiatry Hum Dev. 2010;41(2):168-92.

35. Van Roy B, Groholt B, Heyerdahl S, Clench-Aas J. Self-reported strengths and difficulties in a large Norwegian population 10-19 years: age and gender specific results of the extended SDQ-questionnaire. Eur Child Adolesc Psychiatry. 2006;15(4):189-98

36. Goodman R. The Strengths and Difficulties Questionnaire. J Child Psychol Psychiatry. 1997;38:5.

37. Hollingshead AB. Two factor index of social positions. New Haven, CT: Yale University; 1958.

38. World Health Organization. The ICD-10 Classification of Mental and Behavioural Disorders: Clinical Descriptions and Diagnostic Guidelines. Geneva: World Health Organization; 1992.

39. Norwegian Directorate of Health. Veileder i diagnostikk og behandling av AD/HD. [ADHD diagnostic and treatment guideline]. Oslo: Norwegian Directorate of Health; 2014.

40. Subcommittee on Attention-Deficit/Hyperactivity Disorder; Steering Committee on Quality Improvement and Management, Wolraich M, Brown L, Brown RT, DuPaul G, et al. ADHD: Clinical practice guideline for the diagnosis, evaluation, and treatment of attention-deficit/hyperactivity disorder in children and adolescents. Pediatrics. 2011;128(5):1007-22.

41. American Psychiatric Association. Diagnostic and statistical manual of mental disorders. $4^{\text {th }}$ edition, revised version. Washington DC: American Psychiatric Association; 2000

42. Gomez R. ADHD and hyperkinetic disorder symptoms in Australian adults: descriptive scores, incidence rates, factor structure, and gender invariance. J Atten Disord. 2013. doi:10.1177/1087054713485206

43. Barkley RA, Murphy K. R. Attention-deficit hyperactivity disorder. A clinical workbook. 3rd ed. New York: The Guilford Press; 2006.

44. Becker A, Steinhausen HC, Baldursson G, Dalsgaard S, Lorenzo MJ, Ralston SJ, et al. Psychopathological screening of children with ADHD: Strengths and Difficulties Questionnaire in a pan-European study. Eur Child Adolesc Psychiatry. 2006;15 Suppl 1:156-62.

45. Goodman R. Psychometric properties of the Strengths and Difficulties Questionnaire. J Am Acad Child Adolesc Psychiatry. 2001;40(11):1337-45.

46. Van Roy B, Veenstra M, Clench-Aas J. Construct validity of the five-factor Strengths and Difficulties Questionnaire (SDQ) in pre-, early, and late adolescence. J Child Psychol Psychiatry. 2008;49(12):1304-12.

47. Friborg $\mathrm{O}$, Hjemdal $\mathrm{O}$, Rosenvinge $\mathrm{J}$, Martinussen $\mathrm{M}$. A new rating scale for adult resilience: what are the central protective resources behind healthy adjustment? Int J Methods Psychiatr Res. 2003;12(2):65-76.

48. Jozefiak TMF, Remschmidt $H$. Inventory of life quality in children and adolescents manual, Norwegian version. Stockholm: Hogrefe; 2012

49. Mattejat FRH. Das Inventar zur Erfassung der Lebensqualität bei Kindern und Jugendlichen (ILK) [The inventory of quality of life in children and adolescents (ILC)]. Bern: Hans Huber Verlag; 2006.

50. Jozefiak T, Larsson B, Wichstrom L, Mattejat F, Ravens-Sieberer U. Quality of life as reported by school children and their parents: a cross-sectional survey. Health Qual Life Outcomes. 2008:6:34.

51. Muthén LK, Muthén BO. Mplus user's guide. 7th ed. Los Angeles: Muthén \& Muthén; 1998-2012

52. Raykov T, Marcoulides GA. Model-testing and fit evaluation. In: Raykov T, Marcoulides GA, editors. A first course in structural equation modeling. New Jersey: Lawrence Erlbaum Associates; 2006. p. 38-51.

53. Yu CY. Evaluating cutoff criteria of model fit indices for latent variable models with binary and continuous outcomes. PhD thesis. University of California, Graduate School of Education and Information Studies; 2002

54. Egeland J, Johansen SN, Ueland T. Do low-effort learning strategies mediate impaired memory in ADHD? J Learn Disabil. 2010;43(5):430-40.

55. West SG, Taylor AB, Wu W. Model fit and model selection in structural equation modeling. In: Hoyle RH, editor. Handbook of structural equation modeling. New York: The Guilford Press; 2012

56. Lambek R, Tannock R, Dalsgaard S, Trillingsgaard A, Damm D, Thomsen PH Executive dysfunction in school-age children with ADHD. J Atten Disord. 2011:15(8):646-55

57. Jacobson LA, Williford AP, Pianta RC. The role of executive function in children's competent adjustment to middle school. Child Neuropsychol. 2011;17(3):255-80

58. Langberg JM, Dvorsky MR, Evans SW. What specific facets of executive function are associated with academic functioning in youth with attention-deficit/hyperactivity disorder? J Abnorm Child Psychol. 2013;41(7):1145-59.

59. Ostrander R, Crystal DS, August G. Attention deficit-hyperactivity disorder, depression, and self- and other-assessments of social competence: a developmental study. J Abnorm Child Psychol. 2006;34(6):773-87.

60. Dan O, Raz S. The relationships among ADHD, self-esteem, and test anxiety in young adults. J Atten Disord. 2012. doi:10.1177/1087054712454571

61. Shaw-Zirt B, Popali-Lehane L, Chaplin W, Bergman A. Adjustment, social skills, and self-esteem in college students with symptoms of ADHD. J Atten Disord. 2005:8(3):109-20.

62. Thompson MJ, Laver-Bradbury C, Ayres M, Le Poidevin E, Mead S, Dodds C, et al. A small-scale randomized controlled trial of the revised new forest parenting programme for preschoolers with attention deficit hyperactivity disorder. Eur Child Adolesc Psychiatry. 2009;18(10):605-16.

63. Rapport MD, Orban SA, Kofler MJ, Friedman LM. Do programs designed to train working memory, other executive functions, and attention benefit children with ADHD? A meta-analytic review of cognitive, academic, and behavioral outcomes. Clin Psychol Rev. 2013;33(8):1237-52.

64. Evans SW, Owens JS, Bunford N. Evidence-based psychosocial treatments for children and adolescents with attention-deficit/hyperactivity disorder. Journal J Clin Child Adolesc Psychol. 2013. doi:10.1080/ 15374416.2013.850700

65. Knouse LE, Safren SA. Current status of cognitive behavioral therapy for adult attention-deficit hyperactivity disorder. Psychiatr Clin North Am. 2010;33(3):497-509.

66. Mitchell JT, McIntyre EM, English JS, Dennis MF, Beckham JC, Kollins SH. A pilot trial of mindfulness meditation training for ADHD in adulthood: impact on core symptoms, executive functioning, and emotion dysregulation. J Atten Disord. 2013. doi:10.1177/1087054713513328.

67. Young S, Bramham J. Cognitive-behavioural therapy for ADHD in adolescents and adults: a psychological guide to practice. 2 nd ed. Oxford: Wiley-Blackwell; 2012.

68. Hoza B. Peer functioning in children with ADHD. J Pediatr Psychol 2007;32(6):655-63.

69. Heiman T. An examination of peer relationships of children with and without attention deficit hyperactivity disorder. School Psych Int. 2005;26(3):330-39.

70. Gardner DM, Gerdes AC. A review of peer relationships and friendships in youth with ADHD. J Atten Disord. doi:10.1177/1087054713501552.

71. McQuade, JD, Vaughn, AJ, Hoza, B, Murray-Close, D, Molina, BS, Arnold, LE, Hechtman, L. Perceived social acceptance and peer status differentially predict adjustment in youth with and without ADHD. J Atten Disord. 2014 doi: $10.1177 / 1087054712437582$

72. Crea TM, Chan K, Barth RP. Family environment and attention-deficit/hyperactivity disorder in adopted children: associations with family cohesion and adaptability. Child Care Health Dev. 2013. doi:10.1111/cch.12112

73. Hurt EA, Hoza B, Pelham Jr WE. Parenting, family loneliness, and peer functioning in boys with attention-deficit/hyperactivity disorder. J Abnorm Child Psychol. 2007;35(4):543-55.

74. Grenwald-Mayes G. Relationship between current quality of life and family of origin dynamics for college students with attention-deficit/hyperactivity disorder. J Atten Disord. 2002;5(4):211-22.

75. Wilmshurst $\mathrm{L}$, Peele M, Wilmshurst $\mathrm{L}$. Resilience and well-being in college students with and without a diagnosis of ADHD. J Atten Disord. 2011;15(1):11-7

76. Jensen PS, Hinshaw SP, Kraemer HC, Lenora N, Newcorn JH, Abikoff HB, et al. ADHD comorbidity findings from the MTA study: comparing comorbid subgroups. J Am Acad Child Adolesc Psychiatry. 2001:40(2):147-58

77. Powell SG, Thomsen PH, Frydenberg M, Rasmussen H. Long-term treatment of ADHD with stimulants: a large observational study of real-life patients. J Atten Disord. 2011;15(6):439-51.

78. Meinzer MC, Pettit JW, Viswesvaran C. The co-occurrence of attention-deficit/ hyperactivity disorder and unipolar depression in children and adolescents: a meta-analytic review. Clin Psychol Rev. 2014;34(8):595-607.

79. Ramtvedt BE, Aabech HS, Sundet K. Minimizing adverse events while maintaining clinical improvement in a pediatric attention-deficit/hyperactivity disorder crossover trial with dextroamphetamine and methylphenidate. J Child Adolesc Psychopharmacol. 2014;24(3):130-39.

80. Skrove M, Romundstad P, Indredavik MS. Resilience, lifestyle and symptoms of anxiety and depression in adolescence: the Young-HUNT study. Soc Psychiatry Psychiatr Epidemiol. 2013;48(3):407-16 
81. Cyranowski JM, Frank E, Young E, Shear MK. Adolescent onset of the gender difference in lifetime rates of major depression: a theoretical model. Arch Gen Psychiatry. 2000;57(1):21-7.

82. Emeh CC, Mikami AY. The influence of parent behaviors on positive illusory bias in children with ADHD. J Atten Disord. doi:2012. 10.1177/1087054712441831.

83. Swanson EN, Owens EB, Hinshaw SP. Is the positive illusory bias illusory? Examining discrepant self-perceptions of competence in girls with ADHD. J Abnorm Child Psychol. 2012;40(6):987-98.

84. Barkley RA. Attention-deficit hyperactivity disorder: a handbook for diagnosis and treatment. New York: Guilford Press; 2006

85. Skogli EW, Teicher MH, Andersen PN, Hovik KT, Oie M. ADHD in girls and boys - gender differences in co-existing symptoms and executive function measures. BMC Psychiatry. 2013;13:298.

86. Dopfner M, Steinhausen HC, Coghill D, Dalsgaard S, Poole L, Ralston SJ, et al. Cross-cultural reliability and validity of ADHD assessed by the ADHD Rating Scale in a pan-European study. Eur Child Adolesc Psychiatry. 2006;15 Suppl 1:146-55.

\section{Submit your next manuscript to BioMed Central and take full advantage of:}

- Convenient online submission

- Thorough peer review

- No space constraints or color figure charges

- Immediate publication on acceptance

- Inclusion in PubMed, CAS, Scopus and Google Scholar

- Research which is freely available for redistribution 